\title{
Heat-related Illness Knowledge and Practices among California Hired Farm Workers in The MICASA Study
}

\author{
Maria STOECKLIN-MAROIS ${ }^{*}$, Tamara HENNESSY-BURT $^{\mathbf{1}}$, \\ Diane MITCHELL ${ }^{1}$ and Marc SCHENKER ${ }^{1}$
}

${ }^{1}$ Department of Public Health Sciences, Center for Health and the Environment, University of California Davis, USA

Received August 11, 2012 and accepted November 7, 2012

\begin{abstract}
Global climate change has great potential for escalating the number and duration of extreme heat events in California. California accounts for $16 \%$ of U.S. crop production, and over 450,000 people are employed in agriculture, with more than two-thirds being of Latino ethnicity. Despite Cal/OSHA regulations which specify that potable water, toilets, shade and rest be provided to agricultural workers, heat related illnesses and deaths still occur. The MICASA Study is a population-based sample of $\mathbf{4 6 7}$ hired farm worker households from Mendota, in California's Central Valley. 474 study participants completing follow-up interview and working in agriculture in the year prior are included in this analysis. Men reported an average of $222 \mathrm{~d}(\mathrm{SD}=69.7)$ of work compared to $148 \mathrm{~d}(\mathrm{SD}=67.3)$ for women $(p<0.0001)$. Over $91 \%$ of participants reported receiving training on heat-related illness, but level of heat illness knowledge was moderate with $\mathbf{7 0 \%}$ responding correctly to 4-5 questions. Knowledge about acclimatization was low, with $44 \%$ severely underestimating the time required, and water consumption was low at an average of 10.7 drinks per day. Results suggest important areas to target for heat illness prevention in farm worker populations and that gender specific approaches may be needed for effective heat illness prevention.
\end{abstract}

Keywords: heat-related illness, Heat stress, Agricultural workers, Farm workers, Knowledge

\section{Introduction}

Heat-related illness causes significant sickness and death, especially in the Central Valley of California, which rates among the most productive agricultural areas in the world. Specific impacts of global climate change suggest that greater climate variability, increases in California's average temperatures, and increases in nighttime low temperatures have greater potential for escalating the number and duration of extreme heat events ${ }^{1)}$. More dramatically, the state has suffered a sharp increase in the frequency of

*To whom correspondence should be addressed.

E-mail: mtstoecklin@ucdavis.edu

(C2013 National Institute of Occupational Safety and Health heat stress events, and it is likely that extreme heat events will continue to increase with global climate change $e^{2-4)}$. In California's two-week heat wave of 2006, there were 16,166 excess hospital visits, 1182 excess hospitalizations and over 400 excess deaths ${ }^{5}$.

Young, relatively healthy individuals, such as manual laborers ${ }^{6,7)}$, military recruits ${ }^{8)}$ and athletes ${ }^{9)}$ represent distinct populations at risk for exertional heat-related illness. Risk factors for exertional heat-related illness include lack of acclimatization, poor physical fitness, and being overweight ${ }^{10-12)}$. In addition, weather conditions (air temperature, radiant heat, and humidity), level of physical activity, type of clothing ${ }^{13)}$, and hydration status may also affect a person's risk for exertional heat-related illness ${ }^{8,13-15)}$.

The Centers for Disease Control and Prevention reported 
that U.S. crop workers suffer a heat-related average annual death rate almost twenty times the national rate of 0.02 per 100,000 civilian workers ${ }^{4)}$. Between 1992 and 2006, an estimated 423 workers in the U.S. died from exposure to environmental heat. While describing heat-related deaths provides insights into the effects of heat exposure on worker health, the impact of heat injury can be challenging to measure, and little data exist describing the scope and scale of heat-related illness. California accounts for $16 \%$ of all U.S. crop production, and over 450,000 people are employed in agriculture, with more than two-thirds being of Latino ethnicity ${ }^{16)}$. Despite California's Occupational Safety and Health Administration's (Cal/OSHA) regulations which specify that potable water, toilets, shade and rest be provided to agricultural workers in the summer, heat related illnesses and deaths still occur ${ }^{17)}$. California's agricultural workers endure extreme working conditions from long hours in the direct sun; they may have restricted ability to drink water, use a toilet, and access shade; and they may lack knowledge of the symptoms of heat stress and how to minimize risk. They also experience greater vulnerabilities from the effects of migration, poverty, low levels of education, poor housing conditions and the seasonality of farm work. Information that would help to understand the workers' perspective is limited ${ }^{18)}$, but this knowledge is necessary to define all the factors contributing to increased vulnerability of agricultural workers from purely physiological to personal and cultural influences.

Therefore, the purpose of the present study is to describe Latino farm workers understanding about heatrelated illness and how they view their own vulnerability to summer heat conditions. Until this knowledge is gathered analyzed and acted upon, this population will remain extremely susceptible to the effect of heat exposure which is only predicted to grow more intense with increased global warming.

\section{Subjects and Methods}

\section{Overall design and rationale}

The Mexican Immigration to California: Agricultural Safety and Acculturation (MICASA) Study is a population-based sample of 467 hired farm worker households from Mendota, in Fresno County. Mendota was chosen because of its large proportion of immigrants from Mexico and Central America and high proportion of agricultural workers. Fresno County experiences hot, dry summers where temperatures in summer months average $98.5^{\circ} \mathrm{F}$ in July and $97.1^{\circ} \mathrm{F}$ in August and where record highs of $115^{\circ} \mathrm{F}$ have been recorded ${ }^{19)}$. Baseline interviews were conducted with cohort participants between January 2006 - April 2007, and follow-up interviews were completed between November 2008 - February 2010. In this analysis, we present data collected at the follow-up interview on knowledge of heat-related illness risks and practices for heat illness prevention.

\section{Household enumeration and sampling procedures}

The goal of the sampling strategy was to select a random, community-based sample of Mexican and Central American farm worker families residing in Mendota, California. A stratified area probability sampling design was used with stratification into one of two census tracts and the census block as the primary sampling unit. Enumerators compiled a list of all dwellings (including houses, apartments, trailers, and garages) within randomly selected blocks. The relationship of the house's occupants, age, gender, ethnicity, involvement in farm work, and years of residence were ascertained at each mapped dwelling. Households with no hired farm workers were mapped but individuals were not enumerated. Further details of the enumeration and sampling procedures are provided elsewhere ${ }^{20)}$.

\section{Household and participant recruitment}

Trained interviewers visited eligible households, explained the purpose and procedures of the project and attempted to recruit both the head of household and spouse. Eligible participants included men and women between the ages of 18-55 yr who self-identified as Mexican or Central American, resided in Mendota at the time of the baseline interview, with at least one household member engaged in farm work for at least $45 \mathrm{~d}$ in the previous year.

\section{Informed consent}

After verification of eligibility, the study objectives and procedures were explained, and individuals were invited to participate. Spanish is the primary language of participants, so all explanations and consents were provided in Spanish. Written consent was obtained from each eligible respondent who agreed to participate in the study. The study procedures were approved by the University of California, Davis Institutional Review Board.

\section{Response rates for study participation}

At baseline interview, 843 adults out of 1,039 eligible individuals (422 men and 421 women) completed an interview, and at follow-up 640 individuals were interviewed. Of those completing follow-up interview, 474 study par- 
ticipants reported working in agriculture in the year prior to follow-up and are included in this analysis.

\section{Survey instrument}

The survey instrument collected information on demographics, occupational and environmental risk factors, home environment, acculturation, smoking status, and health outcomes (respiratory health, injuries, mental health, and reproductive health).

The questionnaire was completed through in-person interviews and required approximately one hour to administer. The survey instrument was developed in both Spanish and English, with back translation to ensure its accuracy. Survey questions relied on relevant existing survey instruments, were developed by consensus among the investigators, and revised after review and pilot testing in the community.

\section{Demographic characteristics}

Age at follow-up interview, sex, income, and education were assessed for inclusion as possible modifying or confounding factors in analysis. Country of birth and years living in the U.S. were also examined as potential contributing factors.

\section{Occupational factors}

Analyses were restricted to individuals reporting working in agriculture in the previous year assessed at followup interview. Total number of years working in agriculture was obtained to create an index of overall longevity doing agricultural work. Additionally, a twelve-month work history evaluated number of days working in agriculture (categorized into quartiles) and primary crops and tasks worked in during this period.

\section{Heat-related illness knowledge and practices}

Questions on the interview related to heat illness focused on four aspects: training and knowledge, hydration, rest and access to shade. A heat knowledge scale was created based upon responses to five questions on heat injury prevention. This knowledge scale ranged from $0-5$, with one point scored for each correct response. "High" knowledge was classified as correct answers to four or more questions (a score of 4-5) with less than four as the reference for logistic modeling.

Concern about personal risk of heat illness was assessed using a Likert scale question with responses ranging from not at all concerned to very concerned. Responses to a question about level of comfort with taking a water break ranged from very uncomfortable to very comfortable. These were both dichotomized into very concerned or very comfortable with other responses collapsed into one category. Questions assessing hydration asked if the employer provided beverages at the worksite, if employees brought their own drinks, and how many times per day they drink employer-provided beverages although the volume of beverages consumed was not assessed. Participants were also asked if they are able to take a break if feeling ill from heat and if shade is available to take breaks from the sun.

\section{Statistical analysis}

Statistical analyses explored the relationship of demographic and work characteristics with the level of heatrelated knowledge, concern about heat illness and level of comfort taking a water break. Preliminary analyses explored the bivariate relationship between selected independent variables and the outcome variables of interest. Based on those results and a priori hypotheses of interest, multivariate survey logistic regression models were constructed. The census tract and census block were included as strata and cluster variables, respectively, in the logistic models in order to account for sources of within-cluster correlation. All models were adjusted for age and gender. Statistical analyses were done using SAS version 9.3 (SAS Institute, Inc., Cary, NC).

\section{Results}

In total, 474 individuals completed follow-up interview and reported working in agriculture during the previous year. Of these, 263 were men and 211 were women, with a mean age of $40(\mathrm{SD}=9.6) \mathrm{yr}$ (Table 1). Two-thirds reported less than primary level of education ( $6 \mathrm{yr}$ or less) and $43 \%$ reported annual family incomes less than $\$ 20,000$. Sixty-four percent were Mexican-born, 33\% were born in Central America with the remaining 2\% U.S.-born. Men reported significantly longer residencies in the U.S. compared to women (19.7 $\mathrm{yr}$ vs. $14.8 \mathrm{yr}, p<0.0001)$ as well as more years of experience working in agriculture (19.1 yr vs. $12.9 \mathrm{yr}, p<0.0001)$.

There were also gender differences in the amount and type of agricultural work in the past 12 months, with men reporting an average of $222 \mathrm{~d}(\mathrm{SD}=69.7)$ of work compared to 148 days $(\mathrm{SD}=67.3)$ for women $(p<0.0001)$. Reflecting the primary commodities grown in the Mendota area, melons $(56.5 \%)$, tomatoes $(49.4 \%)$, grapes $(19.2 \%)$ and nuts (19.2\%) were the most frequently reported crops worked by participants, and significantly higher percent- 
Table 1. Demographic and work characteristics among farm workers in the MICASA study, 2008-2010

\begin{tabular}{|c|c|c|c|c|}
\hline Characteristic & $\begin{array}{c}\text { Total }(\mathrm{n}=474) \\
\text { Percent }(\mathrm{n})\end{array}$ & $\begin{array}{c}\text { Male }(n=263) \\
\text { Percent }(n)\end{array}$ & $\begin{array}{c}\text { Female }(\mathrm{n}=211) \\
\text { Percent }(\mathrm{n})\end{array}$ & $p$-value* \\
\hline Age (mean; SD) & $40.4 \pm 9.6$ & $41.2 \pm 9.8$ & $39.4 \pm 9.3$ & 0.1605 \\
\hline \multicolumn{5}{|l|}{ Income } \\
\hline$\$ 0-\$ 19,999$ & $43.4(194)$ & 39.1 (97) & $48.7(97)$ & \multirow[t]{2}{*}{0.0412} \\
\hline$\$ 20,000+$ & $56.6(253)$ & $60.9(151)$ & $51.3(102)$ & \\
\hline \multicolumn{5}{|l|}{ Education } \\
\hline Primary or less & $65.3(309)$ & $69.6(183)$ & $60.0(126)$ & \multirow[t]{2}{*}{0.0296} \\
\hline$>$ Primary & $34.7(164)$ & $30.4(80)$ & $40.0(84)$ & \\
\hline \multicolumn{5}{|l|}{ Country of birth } \\
\hline U.S. & $2.0(9)$ & $2.0(5)$ & $1.9(4)$ & \multirow[t]{3}{*}{0.8325} \\
\hline Mexico & $64.5(293)$ & $65.7(163)$ & $63.1(130)$ & \\
\hline Central America & $33.5(152)$ & $32.3(80)$ & $35.0(72)$ & \\
\hline Years lived in U.S. (mean; SD) & $17.5 \pm 9.5$ & $19.7 \pm 9.3$ & $14.8 \pm 9.0$ & $<0.0001$ \\
\hline Total years worked in agriculture (mean; SD) & $16.4 \pm 9.1$ & $19.1 \pm 9.5$ & $12.9 \pm 7.1$ & $<0.0001$ \\
\hline Days worked in agriculture in past 12 months (mean; SD) & $189.5 \pm 77.9$ & $222.6 \pm 69.7$ & $148.3 \pm 67.3$ & $<0.0001$ \\
\hline $14-126 \mathrm{~d}$ & $25.3(120)$ & $10.7(28)$ & $43.6(92)$ & \\
\hline $127-188 \mathrm{~d}$ & $24.9(118)$ & $21.3(56)$ & $29.4(62)$ & \\
\hline $189-258 \mathrm{~d}$ & $24.9(118)$ & $30.0(79)$ & $18.5(39)$ & \\
\hline$>258 \mathrm{~d}$ & $24.9(118)$ & $38.0(100)$ & $8.5(18)$ & \\
\hline \multicolumn{5}{|l|}{ Crops worked in past 12 months } \\
\hline Melons & $56.5(268)$ & $57.8(152)$ & $55.0(116)$ & 0.5384 \\
\hline Tomatoes & $49.4(234)$ & $52.1(137)$ & $46.0(97)$ & 0.1854 \\
\hline Grapes & $19.2(91)$ & $23.6(62)$ & $13.7(29)$ & 0.0069 \\
\hline Nuts & $19.2(91)$ & $26.2(69)$ & $10.4(22)$ & $<0.0001$ \\
\hline Cotton & $8.9(42)$ & $15.2(40)$ & $1.0(2)$ & $<0.0001$ \\
\hline \multicolumn{5}{|l|}{ Tasks worked in past 12 months } \\
\hline Packing/sorting^ & $43.7(207)$ & $13.3(35)$ & $81.5(172)$ & $<0.0001$ \\
\hline Picking & $31.2(148)$ & $46.4(122)$ & $12.3(26)$ & $<0.0001$ \\
\hline Hoeing/weeding & $27.9(132)$ & $29.3(77)$ & $26.1(55)$ & 0.4383 \\
\hline Pruning & $14.4(68)$ & $20.9(55)$ & $6.2(13)$ & $<0.0001$ \\
\hline Machine operation $\#$ & $12.2(58)$ & $21.7(57)$ & $0.5(1)$ & $<0.0001$ \\
\hline Irrigation $^{++}$ & $12.0(57)$ & $20.5(54)$ & $1.4(3)$ & $<0.0001$ \\
\hline
\end{tabular}

Percent=percentage of participants reporting, $\mathrm{n}=$ number of participants reporting, $\mathrm{SD}=$ standard deviation.

$* \chi^{2}$ tests compare categorical variables and t-test comparisons for continuous variables to examine differences by gender. ${ }^{\wedge}$ Packing/sorting tasks may be done at the field or in processing plant depending on crop; involves sorting commodity by size and placing in boxes for transport. \# Machine operation includes tractor driving, operating other farm equipment, driving trucks. ${ }^{++}$Irrigation tasks include setting up irrigation systems, laying pipe, monitoring watering in field.

ages of men were employed in grapes, nuts and cotton compared to women. The most frequently reported tasks in the past year included packing/sorting (43.7\%), picking (31.2\%), and hoeing/weeding (27.9\%). Women were primarily engaged in packing/sorting tasks $(81.5 \%$ vs. $13.3 \%$, $p<0.0001)$ while men predominated in picking $(46.4 \%$ vs. $12.3 \%, p<0.0001)$, pruning $(20.9 \%$ vs. $6.2 \%, p<0.0001)$, machine operation $(21.7 \%$ vs. $0.5 \%, p<0.0001)$ and irrigation tasks $(20.5 \%$ vs. $1.4 \%, p<0.0001)$.

Over $91 \%$ of participants reported receiving training on heat-related illness although women were significantly more likely to report receiving training compared to men $(p=0.0003)$ (Table 2). Additionally, men and women differed in their level of concern about the risk of heat illness at the workplace with over two-thirds of men compared to $25 \%$ of women reporting they were not at all concerned $(p<0.0001)$. Overall, level of heat knowledge was moderate with $70 \%$ of both men and women responding with the correct answer to 4-5 questions, however, a significantly higher percentage of men responded with correct respons- 
Table 2. Assessment of heat-related knowledge and practices

\begin{tabular}{|c|c|c|c|c|}
\hline Characteristic & $\begin{array}{c}\text { Total }(\mathrm{n}=474) \\
\text { Percent }(\mathrm{n})\end{array}$ & $\begin{array}{c}\text { Male }(\mathrm{n}=263) \\
\text { Percent }(\mathrm{n})\end{array}$ & $\begin{array}{c}\text { Female }(\mathrm{n}=211) \\
\text { Percent }(\mathrm{n})\end{array}$ & $p$-value* \\
\hline Received training about the dangers of working in the heat & $91.6(434)$ & $87.5(230)$ & $96.7(204)$ & 0.0003 \\
\hline \multicolumn{5}{|l|}{ Heat knowledge score* } \\
\hline High $($ score $=4$ or 5$)$ & $70.0(332)$ & $76.1(200)$ & $62.6(132)$ & \multirow[t]{2}{*}{0.0014} \\
\hline Low $($ score $<4)$ & $30.0(142)$ & $23.9(63)$ & $37.4(79)$ & \\
\hline \multicolumn{5}{|l|}{ 'Which of the following are most likely to put you at risk for a heat disorder? } \\
\hline Wearing dark colored clothing while working outdoors (correct answer) & $98.9(486)$ & $98.5(258)$ & $99.5(210)$ & 0.2144 \\
\hline \multicolumn{5}{|l|}{ Amount of time for body to acclimatize to working in heat } \\
\hline$<2 \mathrm{~h}$ & $44.3(210)$ & 44.5 (117) & $44.1(93)$ & \multirow[t]{4}{*}{0.1529} \\
\hline $2-14 \mathrm{~h}$ & $29.1(138)$ & $31.6(83)$ & $26.155)$ & \\
\hline $2-14 \mathrm{~d}$ (correct answer) & $24.3(115)$ & $20.9(55)$ & $28.4(60)$ & \\
\hline $2-14 \mathrm{wk}$ & $2.3(11)$ & $3.0(8)$ & $1.4(3)$ & \\
\hline \multicolumn{5}{|l|}{ 'Which of the following factors can lead to an increased risk of heat stress? } \\
\hline Age & $92.0(436)$ & $90.5(238)$ & $93.8(198)$ & 0.1826 \\
\hline Prior history of heat-related illness & $64.8(307)$ & $75.3(198)$ & $51.7(109)$ & $<0.0001$ \\
\hline Overweight & $95.6(453)$ & $95.1(250)$ & $96.2(203)$ & 0.5448 \\
\hline Employer provides beverages at work site & $87.8(416)$ & $79.5(209)$ & $98.1(207)$ & $<0.0001$ \\
\hline Times/day drink employer-provided beverages (mean; SD) & $10.7 \pm 5.7$ & $11.1 \pm 6.1$ & $10.3 \pm 5.3$ & 0.1151 \\
\hline Employee brings his/her own beverages to work site & $29.7(140)$ & $44.9(118)$ & $10.5(22)$ & $<0.0001$ \\
\hline \multicolumn{5}{|l|}{ Comfort level with taking break to drink water } \\
\hline Very comfortable & $79.0(372)$ & $87.0(228)$ & $68.9(144)$ & \multirow[t]{5}{*}{$<0.0001$} \\
\hline Somewhat comfortable & $18.5(87)$ & $11.8(31)$ & $26.8(56)$ & \\
\hline Neither comfortable nor uncomfortable & $0.9(4)$ & $0(0)$ & $1.9(4)$ & \\
\hline A little uncomfortable & $0.9(4)$ & $1.2(3)$ & $0.5(1)$ & \\
\hline Very uncomfortable & $0.9(4)$ & $0(0)$ & $1.9(4)$ & \\
\hline \multicolumn{5}{|l|}{ Level of concern related to risk of heat illness at work } \\
\hline Not at all concerned & $47.1(222)$ & $64.6(170)$ & $25.0(52)$ & \multirow[t]{3}{*}{$<0.0001$} \\
\hline A little concerned & $44.2(208)$ & $30.0(79)$ & $62.0(129)$ & \\
\hline Very concerned & $8.7(41)$ & $5.3(14)$ & $13.0(27)$ & \\
\hline Able to take a 5 min break every hour if experiencing symptoms of heat stress & $89.7(425)$ & $83.7(220)$ & $97.2(205)$ & $<0.0001$ \\
\hline Shaded area available for to take breaks out of the sun & $93.0(440)$ & $88.9(233)$ & $98.1(207)$ & $<0.0001$ \\
\hline
\end{tabular}

Percent $=$ percentage of participants reporting, $\mathrm{n}=$ number of participants reporting.

${ }^{*} \chi^{2}$ tests comparisons to examine differences by gender.

${ }^{\wedge}$ Specific questions used in calculating Heat knowledge score.

es compared to women $(p=0.001)$. While most respondents correctly stated that wearing dark colored clothing, age and being overweight were risk factors for heat stress, only $65 \%$ knew that prior history of heat illness was a risk factor. Additionally, only $24 \%$ responded correctly with the amount of time needed for the body to acclimate to heat (correct answer 2-14 d). In fact, 44\% believed that the body could acclimate in less than two hours.

According to participant responses, most had employers who provided beverages at the work site $(87.8 \%)$, were able to take a five minute break if experiencing heat stress symptoms $(89.7 \%)$, and had shaded area available to take a break out of the sun $(93.0 \%)$. Workers reported drinking employer provided beverages an average of 11 times per day $(\mathrm{SD}=5.7)$, and there were no reporting differences by gender.

Using survey logistic modeling, we assessed factors associated with a high level of knowledge about heat illness, feeling very concerned about heat illness risk and being very comfortable taking a water break when needed. There were significant differences by gender in all three outcome measures. In age-adjusted models, women had more than twice the odds of reporting a high level of concern about heat illness and were significantly less likely to have a high heat knowledge score (OR $=0.53$; 95\%CI: $0.35-0.81)$ 
or feel comfortable taking a water break $(\mathrm{OR}=0.32 ; 95 \%$ CI: $0.20-0.50$ ).

Assessment of occupational factors included years worked in agriculture, days worked in agriculture in the past 12 months, crops and tasks worked in past 12 months, receiving training on the dangers of heat, and level of heat knowledge. Women and those with fewer years working in agriculture were less likely to have high heat knowledge, but these differences became non-significant in models adjusted for age and gender. In comparing quartiles of days worked in agriculture in the past 12 months, workers with fewer days reported greater concerns about heat illness compared to those in the highest quartile (Table 3). Parallel to this, workers in the lowest quartiles of days worked in the past year were significantly less likely to report being comfortable taking a water break, but these differences were no longer significant after adjusting for age and gender. There were few associations with crop and task although those engaged in packing and sorting tasks were significantly less likely to have high heat knowledge $(\mathrm{OR}=0.57 ; 95 \% \mathrm{CI}: 0.38-0.84)$ or to feel comfortable taking a water break (OR=0.42; 95\%CI: $0.25-0.70)$, but these results were no longer significant after adjusting for age and gender. Machine operation task (driving tractors, trucks, heavy farm equipment) was associated with an increased odds of feeling very comfortable taking a water break (AOR=11.0; 95\%CI: 1.46-82.9). In unadjusted models, machine operation was associated with a two-fold increase in the odds of high heat knowledge and irrigation tasks were associated with three-fold increase in the odds of feeling very comfortable taking a water break but both were non-significant upon adjusting for age and gender.

\section{Discussion}

The Intergovernmental Panel on Climate Change (IPCC) has published reports documenting objectively measured climate change endpoints, their causal effects on human health, projections for what to expect in years to come and how these changes will interact with human and environmental health in the future. These IPCC reports indicate an increase in mean global temperature, an increase in the magnitude and frequency of extreme temperature events (days and nights) and, in several high-risk geographic locations, identifies Mediterranean-like climates to be at increased risk for these events ${ }^{2)}$. More importantly, the IPCC identifies populations of low socioeconomic status at particular risk due to concerns related to access to health care, housing conditions, and cultural practices ${ }^{2)}$. It is also clear that outdoor workers, such as agricultural workers, are at potentially high risk given working conditions compounded by immigration status and socioeconomic circumstances. Despite this, relatively little is known about particular risks faced by farm workers and their level of knowledge and individual ability to implement heat illness prevention practices. There is published literature examining knowledge and attitudes related to heat stress and heat illness in older adults ${ }^{21-23)}$ and athletes ${ }^{24)}$, but we are not aware of any assessments of knowledge and practices in farm worker populations.

One of the primary findings from this study and a major strength is the identification of notable differences between male and female farm workers. From an occupational standpoint, women work fewer days in agriculture and are largely engaged in packing and sorting tasks. Although women were more likely to report receiving heat illness prevention training, they reported higher levels of concern about the risk of heat illness at work and were less comfortable taking a water break than men. Since total days working in agriculture is significantly lower for women compared to men, the work may be more intermittent, and therefore women may have less stature with a particular employer (farm owner or labor contractor) resulting in diminished capacity to take necessary precautions for heat illness prevention.

Results related to level of concern and level of comfort taking a water break and work task are likely accounted for by gender differences in the tasks that men and women commonly engage in while working in California agriculture. In fact, many of the differences by crop and tasks became non-significant once models are adjusted for gender. Packing and sorting tasks are largely undertaken by women while machine operation, largely driving tractors, trucks and other heavy farm equipment, is primarily done by men. It may be that these results are driven by gender rather than an innate difference in crop or task, however, one exception to this may be for operating machines. This activity represents a higher-level task, rather than an entry-level job, and these individuals may indeed have more autonomy and job security, enabling them to feel more comfortable taking a break from working in the heat when needed.

While most workers reported receiving training, we did not collect detailed information on specific components of the training, and there is likely variability in the quality of worksite training. There was a moderate level of knowledge among workers about heat illness; most correctly understood that wearing dark clothing, older age and being overweight presented risks for heat stress. However, it is 
Table 3. Factors associated with high heat knowledge, level of concern about heat illness and being very comfortable taking a water break among farm workers in MICASA study

\begin{tabular}{|c|c|c|c|c|c|c|}
\hline \multirow{3}{*}{ Variable } & \multicolumn{2}{|c|}{ High Heat Knowledge } & \multicolumn{2}{|c|}{ "Very Concerned" about Heat Illness } & \multicolumn{2}{|c|}{$\begin{array}{l}\text { "Very Comfortable" } \\
\text { Taking a Water Break }\end{array}$} \\
\hline & Crude & Adjusted $^{*}$ & Crude & Adjusted ${ }^{*}$ & Crude & Adjusted ${ }^{*}$ \\
\hline & OR $(95 \% \mathrm{CI})$ & OR $(95 \% \mathrm{CI})$ & OR $(95 \% \mathrm{CI})$ & OR $(95 \% \mathrm{CI})$ & OR $(95 \% \mathrm{CI})$ & OR $(95 \% \mathrm{CI})$ \\
\hline Age & $1.01(0.99,1.03)$ & - & $1.00(0.97,1.04)$ & - & $0.99(0.96,1.02)$ & - \\
\hline \multicolumn{7}{|l|}{ Sex } \\
\hline Male & reference & reference & reference & reference & reference & reference \\
\hline Female & $0.53(0.34,0.81)$ & $0.53(0.35,0.81)$ & $2.65(1.40,5.04)$ & $2.68(1.40,5.13)$ & $0.33(0.21,0.51)$ & $0.32(0.20,0.50)$ \\
\hline \multicolumn{7}{|l|}{ Income } \\
\hline$\$ 0-\$ 19,999$ & $1.29(0.83,2.01)$ & $1.39(0.87,2.21)$ & $1.61(0.83,3.10)$ & $1.46(0.77,2.79)$ & $0.44(0.26,0.75)$ & $0.47(0.26,0.84)$ \\
\hline$\$ 20,000+$ & reference & reference & reference & reference & reference & reference \\
\hline \multicolumn{7}{|l|}{ Education } \\
\hline Primary or less & $0.96(0.70,1.33)$ & $0.87(0.62,1.23)$ & $1.74(0.78,3.86)$ & $2.02(0.88,4.61)$ & $0.49(0.31,0.80)$ & $0.73(0.26,0.71)$ \\
\hline More than primary & reference & reference & reference & reference & reference & reference \\
\hline \multicolumn{7}{|l|}{ Years worked in agriculture } \\
\hline $0-5 \mathrm{yr}$ & $0.36(0.17,0.76)$ & $0.45(0.16,1.21)$ & $0.57(0.07,4.40)$ & $0.30(0.04,2.42)$ & $0.39(0.13,1.20)$ & $0.50(0.17,1.49)$ \\
\hline $6-10 \mathrm{yr}$ & $0.87(0.55,1.36)$ & $0.94(0.53,1.67)$ & $2.27(1.12,4.61)$ & $1.63(0.68,3.93)$ & $0.87(0.50,1.54)$ & $0.90(0.40,2.03)$ \\
\hline $11-20 \mathrm{yr}$ & $0.58(0.35,0.94)$ & $0.60(0.33,1.11)$ & $1.90(1.01,3.58)$ & $1.50(0.67,3.37)$ & $0.76(0.41,1.41)$ & $0.76(0.35,1.65)$ \\
\hline $21+\mathrm{yr}$ & reference & reference & reference & reference & reference & reference \\
\hline \multicolumn{7}{|l|}{ Days worked in agriculture in past 12 months } \\
\hline $14-126 \mathrm{~d}$ & $0.78(0.47,1.29)$ & $1.14(0.60,2.16)$ & $7.04(1.70,29.2)$ & $4.37(1.11,17.1)$ & $0.41(0.20,0.82)$ & $0.78(0.32,1.88)$ \\
\hline $127-188 \mathrm{~d}$ & $0.70(0.40,1.24)$ & $0.89(0.46,1.69)$ & $7.32(1.80,29.8)$ & $5.42(1.37,21.4)$ & $0.46(0.25,0.85)$ & $0.69(0.37,1.28)$ \\
\hline $189-258 \mathrm{~d}$ & $1.31(0.71,2.40)$ & $1.49(0.79,2.80)$ & $7.25(1.56,33.7)$ & $6.30(1.40,28.3)$ & $0.76(0.43,1.35)$ & $0.93(0.48,1.78)$ \\
\hline More than $258 \mathrm{~d}$ & reference & reference & reference & reference & reference & reference \\
\hline \multicolumn{7}{|l|}{ Crops worked in past 12 months $^{* *}$} \\
\hline Melons & $1.35(0.97,1.86)$ & $1.34(0.98,1.84)$ & $1.99(0.95,4.15)$ & $2.12(1.00,4.51)$ & $1.12(0.74,1.69)$ & $1.05(0.69,1.62)$ \\
\hline Tomatoes & $1.33(0.91,1.95)$ & $1.29(0.88,1.91)$ & $0.79(0.47,1.34)$ & $0.84(0.48,1.46)$ & $0.93(0.66,1.32)$ & $0.84(0.59,1.21)$ \\
\hline Grapes & $1.16(0.62,2.19)$ & $1.06(0.57,1.96)$ & $1.01(0.50,2.07)$ & $1.20(0.58,2.49)$ & $0.86(0.49,1.50)$ & $0.69(0.40,1.19)$ \\
\hline Nuts & $0.95(0.62,1.46)$ & $0.80(0.51,1.26)$ & $0.56(0.19,1.62)$ & $0.71(0.23,2.21)$ & $2.78(1.29,4.76)$ & $1.87(0.99,3.53)$ \\
\hline Cotton & $0.84(0.43,1.65)$ & $0.60(0.30,1.17)$ & $0.79(0.26,2.39)$ & $1.33(0.39,4.53)$ & $1.66(0.57,4.86)$ & $0.97(0.33,2.85)$ \\
\hline \multicolumn{7}{|l|}{ Tasks worked in past 12 months ${ }^{\wedge}$} \\
\hline Packing/sorting & $0.57(0.38,0.84)$ & $0.78(0.47,1.29)$ & $2.45(1.29,4.67)$ & $1.55(0.58,4.17)$ & $0.42(0.25,0.70)$ & $0.79(0.43,1.45)$ \\
\hline Picking & $1.75(0.95,3.23)$ & $1.44(0.73,2.81)$ & $0.90(0.41,2.01)$ & $1.47(0.65,3.33)$ & $1.06(0.67,1.67)$ & $0.58(0.34,1.02)$ \\
\hline Hoeing & $0.84(0.56,1.26)$ & $0.83(0.55,1.24)$ & $0.96(0.45,2.02)$ & $1.02(0.48,2.16)$ & $0.82(0.50,1.33)$ & $0.72(0.44,1.17)$ \\
\hline Pruning & $0.95(0.55,1.65)$ & $0.77(0.43,1.38)$ & $0.28(0.07,1.22)$ & $0.37(0.09,1.63)$ & $1.29(0.58,2.84)$ & $0.87(0.37,2.06)$ \\
\hline Machine operation $\#$ & $1.96(1.00,3.84)$ & $1.48(0.67,3.27)$ & $0.54(0.14,2.09)$ & $0.94(0.25,3.49)$ & $17.73(2.5,125.7)$ & $11.0(1.46,82.9)$ \\
\hline Irrigation $^{++}$ & $1.11(0.72,1.71)$ & $0.80(0.50,1.30)$ & $0.55(0.18,1.67)$ & $0.90(0.24,3.41)$ & $3.05(1.24,7.54)$ & $1.86(0.71,4.89)$ \\
\hline $\begin{array}{l}\text { Received NO training about dangers of working } \\
\text { in heat }\end{array}$ & $1.14(0.56,2.32)$ & $0.94(0.47,1.89)$ & $0.53(0.12,2.27)$ & $0.72(0.16,3.25)$ & $2.47(0.72,8.45)$ & $1.75(0.52,5.88)$ \\
\hline $\begin{array}{l}\text { "Low" heat knowledge score (score = less than } \\
4 \text { out of 5) }\end{array}$ & - & - & $2.45(0.56,10.72)$ & $2.46(0.55,11.0)$ & $1.72(0.88,3.38)$ & $1.92(0.89,4.10)$ \\
\hline
\end{tabular}

$\mathrm{OR}=$ odds ratio, $95 \% \mathrm{CI}=95 \%$ confidence interval.

* Models adjusted for age and gender. ^ Packing/sorting tasks may be done at the field or in processing plant depending on crop; involves sorting commodity by size and placing in boxes for transport. ${ }^{\#}$ Machine operation includes tractor driving, operating other farm equipment, driving trucks. ${ }^{++}$Irrigation tasks include setting up irrigation systems, laying pipe, monitoring watering in field. ${ }^{* *}$ Reference for each crop type is those who did not work the specific crop in the last 12 months, (ie. for melons, the reference is those who did not report work in melons in past 12 months). ${ }^{\wedge}$ Reference for each task is those who did not engage in the particular task in the last 12 months (ie. for packing/sorting, the reference is those who did not report doing packing/sorting tasks in the past 12 months). 
clear from these results that there is a lack of knowledge about the amount of time required to appropriately acclimate to hot working conditions since almost half of both men and women believed that less than two hours was sufficient time. Acclimatization benefits agricultural workers by providing increased tolerance to heat stress ${ }^{6,18)}$, however, the seasonality of farm work and inherent variability in securing and maintaining work may play a role in workers' ability to acclimate to hot working conditions.

Further, water consumption reported by both men and women in this study is likely insufficient to insure proper hydration. According to Cal/OSHA, employers are not only required to provide workers with clean and cool drinking water, they must also encourage workers to drink an 8-ounce cup of water every 15 min to maintain hydration and counter body fluid loss when working outdoors in conditions of extreme heat ${ }^{25}$. If we make the assumption that workers spend six hours working in the heat, the recommendation would suggest consuming 8-ounces of water 24 times over the course of this time period. While the study did not collect the volume of fluids consumed, the overall average of drinks per day reported by participants in this study was 10.7 , a level far below recommendations and unlikely to replenish fluids and maintain appropriate hydration for good health and performance ${ }^{18)}$. However, we do not have data to provide information on the reasons for low levels of consumption-whether workers believe that they are drinking sufficient amounts or rather face other individual factors or situational conditions that preclude adequate consumption. These include perceived "costs" associated with accessing drinking water such as lost wages from taking breaks (especially among piece-work earners), negative reactions from co-workers or supervisors, lack of nearby bathroom facilities, and unsanitary facilities. Hydration is a key issue among farm workers since it is also reasonable that during several consecutive days of working in hot temperatures, workers may begin a shift without fully rehydrating from the previous day ${ }^{18,26)}$.

A recent study of farm workers in North Carolina reported that while $94 \%$ of respondents worked in conditions of extreme heat, $40 \%$ of them reported symptoms of heat illness ${ }^{27)}$. Furthermore, workers with authorization drank more water, took more breaks and changed work hours and activity to a greater extent than those working without authorization. While we did not have authorization status on participants, we examined other immigration factors including country of birth and number of years living in the U.S. None of these factors was associated with high heat knowledge, level of concern with heat illness or level of comfort requesting a water break. Since workers in the study were recruited based upon occupation as a farm worker at baseline interview and therefore had a minimum residency in the U.S., it may be that in this population, factors such as age, sex, education and income were more important determinants.

Some limitations to this study should be noted, primarily the reliance on self-report by study participants. This is an initial attempt to assess heat knowledge and practices among farm workers to gain understanding of issues and concerns in this population. Interpretation of data for crop and task is challenging since workers often have more than one employer over a season of work and engage in a number of crops and tasks. Another limitation is the emphasis on recruitment of family farm worker households. Unaccompanied males are an important constituent of the farm worker population in California but were excluded from the MICASA study since these workers tend to be more migrant. This concession was made to improve longterm follow-up with cohort participants. While there may be factors related to knowledge and heat illness prevention practices unique to this segment of the farm worker population, participants in the MICASA study have demographic profiles similar to the National Agricultural Workers Study (NAWS) and California Agricultural Workers Health Study (CAWHS) ${ }^{28,29)}$.

\section{Conclusions}

In conclusion, these results suggest a number of important areas to target for heat illness prevention programs in farm working populations. Understanding the process of acclimatization and the risk to workers for heat illness should be an objective of educational programs. More research is also required to clarify water consumption patterns during work hours and the reasons that workers do not drink frequently enough to insure proper hydration. Additionally, the differences between men and women suggest that gender specific approaches may be necessary for effective awareness and heat illness prevention.

\section{Funding disclosure}

This research was funded by the National Institute of Occupational Safety and Health (NIOSH) (1RO10H009293 and 2U50OH007550) and The California Endowment. 


\section{References}

1) California Department of Public Health (2008) Public health impacts of climate change in California: Community Vulnerability Assessments and Adaptation Strategies. Report No.1. Climate Change Public Health Impacts Assessment and Response Collaborative, Sacramento.

2) Parry ML, Intergovernmental Panel on Climate Change Working Group II (2007) Climate change 2007: impacts, adaptation and vulnerability: contribution of Working Group II to the fourth assessment report of the Intergovernmental Panel on Climate Change. U.K.; Cambridge University Press, Cambridge, New York.

3) Kjellstrom T, Holmér I, Lemke B (2009) Workplace heat stress, health and productivity - an increasing challenge for low and middle-income countries during climate change. Glob Health Action 2.

4) CDC (2008) Heat-related deaths among crop workersUnited States, 1992-2006. MMWR Morb Mortal Wkly Rep 57, 649-53. [Medline]

5) Knowlton K, Rotkin-Ellman M, King G, Margolis HG, Smith D, Solomon G, Trent R, English P (2009) The 2006 California heat wave: impacts on hospitalizations and emergency department visits. Environ Health Perspect 117, 61-7. [Medline]

6) Bonauto D, Anderson R, Rauser E, Burke B (2007) Occupational heat illness in Washington State, 1995-2005. Am J Ind Med 50, 940-50. [Medline] [CrossRef]

7) Donoghue AM (2004) Heat illness in the U.S. mining industry. Am J Ind Med 45, 351-6. [Medline] [CrossRef]

8) Kark JA, Burr PQ, Wenger CB, Gastaldo E, Gardner JW (1996) Exertional heat illness in Marine Corps recruit training. Aviat Space Environ Med 67, 354-60. [Medline]

9) Murphy RJ (1984) Heat illness in the athlete. Am J Sports Med 12, 258-61. [Medline] [CrossRef]

10) Gardner JW, Kark JA, Karnei K, Sanborn JS, Gastaldo E, Burr P, Wenger CB (1996) Risk factors predicting exertional heat illness in male Marine Corps recruits. Med Sci Sports Exerc 28, 939-44. [Medline] [CrossRef]

11) Epstein Y, Moran DS, Shapiro Y, Sohar E, Shemer J (1999) Exertional heat stroke: a case series. Med Sci Sports Exerc 31, 224-8. [Medline] [CrossRef]

12) Wallace RF, Kriebel D, Punnett L, Wegman DH, Wenger CB, Gardner JW, Kark JA (2006) Risk factors for recruit exertional heat illness by gender and training period. Aviat Space Environ Med 77, 415-21. [Medline]

13) Carter JB, Banister EW, Morrison JB (1999) Effectiveness of rest pauses and cooling in alleviation of heat stress during simulated fire-fighting activity. Ergonomics 42, 299-313. [Medline] [CrossRef]

14) Mirabelli MC, Richardson DB (2005) Heat-related fatalities in North Carolina. Am J Public Health 95, 635-7. [Medline] [CrossRef]

15) Donoghue AM, Sinclair MJ, Bates GP (2000) Heat exhaustion in a deep underground metalliferous mine. Occup Environ Med 57, 165-74. [Medline] [CrossRef]

16) State of California, Employment Development Department (EDD) (2008) California's Agricultural Employment, 2008.

17) DIR (2010) Targeted heat illness prevention campaign: 2010 Report to the Legislature.

18) Jackson LL, Rosenberg HR (2010) Preventing heat-related illness among agricultural workers. J Agromedicine 15, 200-15. [Medline] [CrossRef]

19) (NOAA) NOAA (NowData-NOAA Online Weather Data. http://www.nws.noaa.gov/ climate/xmacis.php?wfo=hnx. Accessed October 30, 2012.

20) Stoecklin-Marois MT, Hennessy-Burt TE, Schenker MB (2011) Engaging a hard-to-reach population in research: sampling and recruitment of hired farm workers in the MICASA study. J Agric Saf Health 17, 291-302. [Medline]

21) Ibrahim JE, McInnes JA, Andrianopoulos N, Evans S (2012) Minimising harm from heatwaves: a survey of awareness, knowledge, and practices of health professionals and care providers in Victoria, Australia. Int J Public Health 57, 297-304. [Medline] [CrossRef]

22) Sheridan SC (2007) A survey of public perception and response to heat warnings across four North American cities: an evaluation of municipal effectiveness. Int J Biometeorol 52, 3-15. [Medline] [CrossRef]

23) Abrahamson V, Wolf J, Lorenzoni I, Fenn B, Kovats S, Wilkinson P, Adger WN, Raine R (2009) Perceptions of heatwave risks to health: interview-based study of older people in London and Norwich, UK. J Public Health (Oxf) 31, 119-26. [Medline]

24) Shendell DG, Alexander MS, Lorentzson L, McCarty FA (2010) Knowledge and awareness of heat-related morbidity among adult recreational endurance athletes. Int J Biometeorol 54, 441-8. [Medline] [CrossRef]

25) CDOSH (2006) Heat Illness Prevention Regulations \# 3395. California Code of Regulations. Vol Title 8 (Section 3395).

26) Kenefick RW, Sawka MN (2007) Hydration at the work site. J Am Coll Nutr 26, 597S-603S. [Medline]

27) Mirabelli MC, Quandt SA, Crain R, Grzywacz JG, Robinson EN, Vallejos QM, Arcury TA (2010) Symptoms of heat illness among Latino farm workers in North Carolina. Am J Prev Med 39, 468-71. [Medline] [CrossRef]

28) Villarejo D, McCurdy SA (2008) The California agricultural workers health survey. J Agric Saf Health 14, 135-46. [Medline]

29) U.S.DOL (2005) The national agricultural workers survey Washington, DC: Employment and Training Administration. 